REVISTA ANDALUZA DE ANTROPOLOGÍA.

NÚMERO 10: ANTROPOLOGÍA Y EPISTEMOLOGÍAS DEL SUR: EL RETO DE LA DESCOLONIZACIÓN DE LA PRODUCCIÓN DEL CONOCIMIENTO

MARZO DE 2016

ISSN 2174-6796

[pp. 29-53]

http://dx.doi.org/10.12795/RAA.2016.10.03

Recibido: $30 / 12 / 2015$

Aceptado: 20/01/2016

\title{
SER Y SENTIR FLAMENCO: DESCOLONIZANDO LA ESTÉTICA MODERNO COLONIAL DESDE LOS BORDES
}

\section{BEING AND FEELING FLAMENCO: DECOLONIZING THE COLONIAL MODERN AESTHETICS FROM THE BORDERS}

\author{
Iván Periáñez Bolaño ${ }^{1^{*}}$ \\ Universidad de Sevilla
}

\section{Resumen.}

Este artículo muestra cómo las formas expresivas flamencas andaluzas originadas, producidas y circuladas en contextos específicos y singulares, forman un corpus de conocimientos y saberes vernáculos que van más allá del acto musical, y que hemos denominado epistemología del sentir situada. Se posiciona frente a la noción de arte sustentada en la estética kantiana y el racionalismo cartesiano, así como a la colonialidad del ojo sobre los demás sentidos. Al monopolio de la lectoescritura se contrapone la oralidad y la música (cantada, bailada, sonora) en tanto que planos discursivos de la realidad social que establecen relaciones de sentido, resistencia y (auto)representación, desde la que expresan su singularidad los miembros y grupos que producen tales

1. Este artículo se enmarca en la tesis doctoral que realiza el autor sobre un análisis comparado de expresiones musicales vernáculas en el entorno mediterráneo, financiado por el Ministerio de Educación, Cultura y Deporte para el periodo 2014-2018, en el marco del Programa Estatal para el Talento y la Empleabilidad de la Formación del Profesorado Universitario (2013-2016). 
manifestaciones. La epistemología del sentir flamenca se presenta así como un conjunto de conocimientos situados producto del aprendizaje vernáculo, las relaciones interpersonales y la reproducción grupal. Es este un ejercicio de aesthesis decolonial.

\title{
Palabras claves.
}

Flamenco, Andalucía, gitanos, conocimiento situado, aesthesis decolonial, epistemologías del sentir

\begin{abstract}
.
This article shows how expressive forms of andalusian flamenco which are originated, produced and flowed in a specific and particular context, become in a corpus of vernacular knowledge that go beyond the musical act. This corpus of knowledge is named epistemología del sentir situada. This epistemology is positioned against art concepts of Kantian esthetic and Cartesian rationalism and, the colonialism of the eye over the other senses. The monopoly of reading and writing is opposed to oral expression and music (sung, danced, sound) considering that they belong to a discursive level of social reality where is establishing relations of sense, resistance and (self) representation between members and groups who produced these manifestations. From this context, members and groups express their uniqueness. Epistemología del sentir flamenca is presented as a set of situated knowledge which is result of vernacular learning, interpersonal relationships and collective social reproduction. This is an exercise of decolonial aesthesis.
\end{abstract}

\section{Keywords.}

Flamenco, Andalusia, gipsy, situated knowledge, decolonial aesthesis, epistemologías del sentir

El interés suscitado por el flamenco en el circuito global de las denominadas "músicas del mundo" (Ochoa, 2002) o étnicas, se ponen en relación con los procesos políticos de patrimonialización destacando la inclusión del flamenco en la Lista Representativa del Patrimonio Cultural Inmaterial de la UNESCO (2010), así como su tratamiento específico en cuanto a patrimonio etnológico en la política cultural y patrimonial de Andalucía. Ello ha propiciado una re-semantización de esta expresión en los circuitos de consumo global, en el que el aporte de "lo gitano" refuerza los mecanismos tradicionales de exotización en los procesos hegemónicos actuales de construcción, reproducción y mercantilización de la alteridad. 
Sin embargo, este flamenco construido como producto cultural para ser consumido, se origina y articula desde formas expresivas vernáculas traídas de la memoria mediante la condensación de elementos comunicativos y expresivos singulares que sobrepasan la lógica formal y medida de las músicas institucionalizadas. El proceso de significación, en estos casos, pone en juego los sonidos, los ritmos y la memoria producidos en el plano de la oralidad y las relaciones grupales situadas. Es más, desde aquí suponen un corpus de conocimientos relacionados con lo sentido-vivido y "las heridas coloniales" (Anzaldúa, 2012), todavía abiertas aunque resignificadas en el contexto andaluz, español y europeo, y que hemos denominado epistemologías del sentir.

Reconocer las formas expresivas flamencas como conjunto de conocimientos y saberes vernáculos, patrimonio inmaterial de grupos subalternizados, desde y con los que se construye sentido, es dar cuenta de un "giro epistemológico" (Barriendos, 2007; Mignolo, 2010) que escapa a las lógicas pasivas contemplativas de la obra de arte en su concepción moderna. Como epistemología que parte de los sentidos y las emociones, descentra la supremacía del ojo supeditándola al saber escuchar y aprender escuchando: este descentramiento permite reconocer por un lado, compartir por otro, cómo se insertan y expresan las marcas heredadas de la subalternidad mediante la articulación de los sonidos y el silencio, con lo sentido y la memoria. Estas epistemologías (del sentir) musicales se sitúan, a su vez, como expresiones en las que los grupos situados en los bordes del proyecto modernizador se reconocen y son reconocidos. Traducir la pluralidad de las formas flamencas como epistemologías del sentir, sitúa y visibiliza las marcas heredadas e infringidas por la "colonialidad del ser" (Maldonado Torres, 2007, 2008) y los sentidos. Y por tanto, pone el acento no sólo en los procesos de colonialidad sobre los grupos minorizados y sus formas de expresividad, sino además, cómo ser y sentir flamenco suponen formas otras de descolonizar el imaginario y la estética moderno/colonial. Este artículo, es por ello, un alegato en favor de la diversidad y pluralidad del mundo, y de las distintas opciones epistémicas que las conforman. Supone, para el caso del flamenco(s), situar en/desde narrativas y prácticas concretas "las epistemologías del sur" (Santos, 2011; Santos y Meneses, 2014), en tanto que propuesta alternativa procedente de una de las periferias del Sur global (Meneses, 2011) y de uno de los grupos más castigados por la modernidad: los y las gitanas (en este caso, flamencos y andaluzas) ${ }^{2}$.

2. Estamos de acuerdo con Pedro Peña (2013), Alfredo Arrebola (2011), Emmanuel Lizcano (2006), Antonio Machado y Álvarez "Demófilo" (1878), Ricardo Molina y Antonio Mairena (1971), Manuel Ríos Ruiz (1971), entre otros, y para esta cuestión, que el flamenco no supone un corpus de conocimientos, saberes y expresiones musicales homogéneo y unitario. De entre la pluralidad de formas y de grupos creadores de eso que llamamos flamenco, este artículo toma aquellas cuyos protagonistas y transmisores son las y los gitanos flamencos andaluces. Por tanto, cuando empleemos el vocablo "flamenco(s)" nos estamos refiriendo a una de sus formas existentes. Y ello, porque entendemos que diluir a los colectivos protagonistas en un homogéneo flamenco, no dejaría de ser un acto de colonialidad interna. 


\section{1. "PRESUMES QUE ERES LA CIENCIA, Y YO NO LO COMPRENDO ASII"}

Pensar en las formas expresivas flamencas como epistemología del sentir situada, es reconocer la capacidad que los sentidos y las experiencias tienen en la producción del conocimiento. Bien es cierto que de un conocimiento otro que supera las dualidades del tipo objetividad/subjetividad, ya que la subjetividad conecta con las vivencias compartidas y no con los métodos de validación y los objetivos de la ciencia racional occidental. En su dimensión musical, desaparece la rigidez del pentagrama y los ritmos de conservatorio, tan alejados de los procesos de aprendizaje no institucionalizados ni formales desde los que se crean, originan y transmiten el patrimonio oral e inmaterial que suponen estos saberes.

$\mathrm{Y}$ este es un terreno donde la ciencia racional no se encuentra cómoda. El lenguaje científico hegemónico tiene dificultades para traducir aquello que no (re)conoce, que no ha aprendido a reconocer, o bien ha destruido, oprimido, dominado y silenciado, cuando no categorizado como un proceso homogéneo y de una única dirección:

"El hecho de poseer un cultura ágrafa, basada en la tradición oral, nos convierte en frágiles y muy vulnerables. Parece increíble cómo los gitanos podamos ser teóricamente zarandeados y a merced de quienes, sin un basamento sólido, osan esparcir, públicamente, opiniones que merman nuestra credibilidad y trastocan nuestro pasado. Éstos coinciden, con frecuencia, en ser los mismos que niegan la aportación y la creatividad de los gitanos flamencos, en base a que no existen documentos rigurosos que así lo atestigüen. ¡Cuánta ligereza para denigrarnos cuando les viene bien, y cuánto rigor y exigencia para reconocernos como autores de nuestras propias músicas!" (Peña, 2013: 81).

El caso es que un acercamiento a las formas de transmisión y aprendizaje de los conocimientos y saberes que constituyen el ser y sentir flamenco(s), ha de tener en cuenta el plano de la oralidad como elemento fundamental de comunicación y expresión. Como señala Emmanuel Lizcano (2006: 96), "el flamenco es un lenguaje especializado [...] cuyos elementos no son la matematización, la argumentación racional, la definición cerrada", y como tal es desplazado e ignorado en las sociedades "escritocéntricas [...], donde el arte oral ha sido considerado indigno de examen serio, y por lo tanto, no se elaboran conceptos que ayuden a comprenderlo" (Sánchez, 2004: 49-50). Este es, uno de los retos de la perspectiva decolonial y las epistemologías del sentir: desproveer al lenguaje del sentido escrito y pensarlo oral.

La relevancia de la oralidad es central puesto que reconoce una comunidad de sentido que nos habla de un proceso vivo. Y porque es vivido es inasible, y esto, que es un

3. Fragmento de cante por soleá, completo sería: "presume que eres la ciencia/yo no lo comprendo así/porque siendo tú la ciencia/me había comprendío a mî". 
problema para las perspectivas racionales, no lo es tanto desde las epistemologías del sentir. Lo relevante reside en no separar el arte de la vida (Saiko, 2012), ni deslindar las expresiones artísticas de la cotidianidad y de cómo están entretejidas en las formas de ser y sentir de las personas, grupos y colectivos que transmiten y se autorrepresentan a través de las mismas. Se es flamenco o flamenca en todo momento, no es un disfraz o una segunda piel que se utiliza en relación a un acto o manifestación musical concreta, uno es, está, siente flamenco todo el tiempo. La cuestión es de cosmovisión, de ver y situarse en el mundo desde formas singulares que cuentan con expresiones musicales para poder comunicar los sentidos y la memoria: ser flamenco es sentir, expresar y conocer situado en el mundo. En este caso, y por ello, las formas flamencas corresponden a procesos sonoros y corporales que van más allá del hecho musical aislado.

Y este es uno de los retos de las ciencias sociales y su producción epistemológica. Reconocer la afectividad, las emociones, el sentir situado, las experiencias, las vivencias y la subjetividad, como parte relevante del conocimiento y los saberes no hegemónicos. Ello requiere, al menos, situarse y reconocerse desde/en los márgenes del conocimiento eurocentrado para "desbordar la racionalidad del pensamiento y la metodología de la visión" (Gimeno y Castaño, 2014: 214). Por otro, necesita "corazonar las epistemologías" (Guerrero, 2010), en tanto que la ciencia hegemónica ha colonizado y/o negado aquellas formas otras de conocimiento que se perciben y transmiten desde los demás sentidos, así como de las emociones que éstos producen y construyen. La dificultad que plantea Santos (2014) es la falta de epistemologías todavía por construir, desde un lenguaje creativo y sentido-compartido, "que haga visibles las alternativas epistémicas que permitan tener en cuenta la diversidad de experiencias y saberes [...] con el objetivo de (re)construir la cartografía de los saberes y las experiencias de la humanidad" (Meneses, 2011: 33) no narradas por la modernidad/colonialidad.

Y para ello, es necesario un lenguaje que dé cuenta de la pluralidad de sentidos. Es así como las formas flamencas se reconocen y construyen como epistemología del sentir situada, mediante procesos de conversación (alternativa al diálogo) en el sentido "nometodológico" señalado por Alejandro Haber (2011: 19): "reconociendo que la conversación nos puede interpelar [...], lo que nos ayuda a reconocer y aprender en relación con otros". Lo relacional es relevante, en tanto que desplaza la importancia de quien escribe al mismo plano de quienes participan de la conversación: al menos, de las voces y posiciones de los y las co-protagonistas que forman parte de la misma, de las narrativas y perspectivas de los y las autoras que aparecen en el texto, de la voz del autor; en este caso, desde un yo colectivo en el que me autoadscribo y desde el que me autorrepresento; y aquellas voces que al leer este documento deseen desplazar la fijación de la imagen que suponen las palabras, hacia los sonidos y significados que evocan. 
Es de esta manera como las epistemologías del sentir fluyen entre los intersticios del dominio colonial que prefija el diálogo, ampliando las voces, las relaciones y las posibilidades de (re)conocimiento entre cosmovisiones y posiciones epistémicas. La conversación, a diferencia del diálogo, no requiere representación (delegar, que otros nos representen, que hablen por nosotros) sino que es un acto/proceso de autorrepresentación personal y compartida: democrática, si se quiere. Diluye los antagonismos, las dualidades y la objetividad, y se posiciona en las diferencias y diferentes posiciones subjetivas e intersubjetivas. Diluye la objetivación de los discursos mediados, buscando borrar las jerarquías de saber establecidas en la no-relación objeto-sujeto. Pensar en el flamenco(s) como epistemología del sentir situada requiere descentrar la literalidad del texto para activar o expandir la creatividad epistémica a la que venimos aludiendo. Por tanto, a ser posible, léase sin mirar, léase escuchando.

\section{PENSANDO EL FLAMENCO(S) COMO EPISTEMOLOGÍA DEL SENTIR SITUADA}

Pensar en las formas expresivas flamencas como epistemologías del sentir ha consistido y consiste en un trabajo de "co-labor" (Rappaport, 2008) que, como decimos, es resultado de conversaciones relacionales producidas en distintos procesos donde se subrayan las opiniones y discursos de los y las participantes protagonistas: de sus historias de vida, de conversaciones esporádicas y voces entrelazadas, de entrevistas, de mis experiencias y vivencias como flamenco, así como del legado que suponen los cantes y sus letras. Siempre despacito y a compás, hemos pensado el flamenco(s) como un corpus de conocimientos y saberes situados en base a los siguientes procesos y elementos característicos. La conversación sigue abierta:

\subsection{Flamenco(s), aprendizaje vernáculo de un Patrimonio Inmaterial}

En tanto que los saberes y conocimientos que los conforman se constituyen en/desde procesos de aprendizaje no institucionalizados, suponiendo, en cualquiera de sus manifestaciones, la forma de expresar unas maneras de vivir, de sentir, de conocer y de emocionarse. En estos casos, la desinstitucionalización es uno de los elementos característicos del proceso de aprendizaje del ser y sentir flamenco(s), así como de sus formas musicales, ya que es resultado de relaciones familiares, interfamiliares y comunitarias producidas en contextos de pertenencia (casas de amigos y familiares, barrios, plazas, bares, peñas) y momentos significativos (bodas, bautizos, pedimentos, cumpleaños o fiestas como la Navidad).

La transmisión, necesaria para que se establezca la comunicación, el aprendizaje y la continuidad de estos conocimientos y saberes, requiere de una comunidad y espacios 
de participación donde el flamenco(s) se presenta como un elemento clave que articula procesos de sociabilidad mediante relaciones simbólicas concretas ${ }^{4}$. Es claro que, para que esa epistemología esté presente en la actualidad, tiene que haber una colectividad que la comparta y la ponga en circulación: si la ponen en circulación es porque tiene sentido, esa es la base de la comunicación

"vivencias que he experimentao en el seno íntimo de mi familia y en las relaciones de mi familia con las demás [...]. Siento dentro de mí la herencia de un legado musical que me viene transmitío por muchas generaciones anteriores, eso sí lo siento: yo no me hice flamenco, el flamenco estaba ya dentro de mí, y yo soy como un eslabón más de esa cadena de tradición. De modo que ya desde el vientre de mi madre yo me crié, nací, crecí y he vivido flamenco toda mi existencia. Yo no fui al flamenco, no era algo que estaba ahí a lo que yo fui porque me entusiasmó, no, el flamenco estaba dentro de mî" (Pedro Peña, 2015)5.

La continuidad o tradición, que podemos traducir por transmisión, aprendizaje, reproducción y circulación de formas expresivas singulares en entornos específicos, es visible en las conversaciones que hemos mantenido con otras personas sobre el mismo asunto. Uno se siente partícipe de una trayectoria compartida, que con matices según los contextos y las familias, se produce en mayor o menor medida según las experiencias vitales de cada uno de nosotros y nosotras. Sirvan de ejemplo estos fragmentos de las historias de vida que realizamos junto a dos flamencos cuyas trayectorias y vivencias son dispares:

"Primero, uno aprende con las emociones. Uno coge el compás, el ritmo y esas cosas de pequeño, no es que te guste directamente el flamenco, sino que está ahí desde que eres pequeño." (Sebastián Peña, 23/10/2015) ${ }^{6}$.

"Yo me he hecho al flamenco, el flamenco vino a mí, estaba ahí, estaba ahí guardaíto pero vino a mí de alguna manera. No sé cómo decirte que el flamenco vino a mí, estaba ahí en tos laos, lo que pasa es que ha sío sin darme cuenta [...]. El flamenco hay que mamarlo, yo

4. Cristina Cruces (2002), Isidoro Moreno (2002) y Cruces y Moreno (1996) han hablado de "valor de uso" en el flamenco para señalar las relaciones producidas para la satisfacción de necesidades colectivas, frente al "valor de cambio", referido a la apropiación, descontextualización y desidentificación de estos procesos.

5. Entrevista aparecida en el Programa "Flamencos y Cronopios", de 8tv Andalucía, el 25 de mayo de 2015, presentado y dirigido por Antonio Ortega. Pedro Peña es de Lebrija, tocaor y cantaor de una de las familias flamencas más extensas: hijo de "Perrate" y la "Perrata", hermano de "El Lebrijano", primo de Pedro Bacán e Inés Bacán, y emparentado, entre otros, con Fernarda y Bernarda de Utrera, El Funi, Gaspar de Utrera, "El Turronero" o "Bambino", por citar algunos.

6. Sebastián Peña (Sebastián Bacán), es guitarrista flamenco no profesional, hijo del gran guitarrista lebrijano Pedro Peña Peña (Pedro Bacán). 
eso no lo relacionaba con flamenco porque eso es lo que siempre he escuchao, y eso pa mí es una cultura de aquí. Yo eso no lo he aprendio con los libros." (Rubén Rubio, 2015)7.

Si bien los procesos de transmisión y aprendizaje se producen desde diversos planos, ambos señalan como elemento común la presencia cotidiana de una memoria colectiva de la que no se es consciente en un primer momento, en tanto que forma parte de un proceso continuo y cotidiano adherido a las distintas generaciones que les/nos precedieron. Sobre esta memoria descansa lo que Antonio García Olivares (2003) denomina una “epistemología popular", cuyos elementos comunes y centrales de transmisión y conocimiento son los y las mayores (sobre todo), los encuentros familiares, los contextos específicos, y en este caso, la relevancia de Andalucía (como sujeto histórico-cultural diverso y plural) en lo relativo al flamenco(s) y a la singularidad de los y las gitanas andaluzas en sus procesos de asentamiento, convivencia, creatividad, participación y protagonismo de/en la tierra de (al menos) las cuatro culturas ${ }^{8}$.

Es así como la presencia y el recuerdo de los y las mayores constituye el primer y fundamental eslabón de transmisión. Ellos articulan lo aprendido en el pasado con las posibilidades y circunstancias presentes, de manera que lo recordado-vivido supone el basamento a través del cual estos saberes vernáculos conforman un patrimonio inmaterial. Esta centralidad separa las formas de aprendizaje mediadas del sistema educativo formal, constituyéndose en un proceso horizontal de relación directa y continua. Es lo que Henry Odera Oruka (1999) denomina "sagacidad filosófica", para señalar que en diversas sociedades y culturas no occidentales contraponen la formación reglada y eurocentrada a "la sabiduría y experiencias de los ancianos" (en HapanyengwiChemhuru, 2013: 44-45). Esta continuidad supone no sólo "la herencia de una filosofía en la que la vida y el arte no se diferencian" (Ortega, 2015)', sino además, que esta "memoria colectiva y filosofía de enseñanza de los mayores suponen una práctica decolonial para la descolonización del ser" (Walsh y García Salazar, 2015: 80): implica sentir con otros e imaginar con otras desbordando la racionalidad del pensamiento occidental, así como sus formas de institucionalización y homogeneización de la diversidad epistémica y de los grupos protagonistas que la producen y circulan en mayor medida.

7. Fragmento de la historia de vida realizada junto a Rubén Rubio, el 23 de septiembre de 2015.

8. Aunque me sitúo en las posiciones críticas de la noción "tres culturas", por el reduccionismo cultural que supone dividir las culturas por la religión monoteísta que se practica, si se diese por bueno, seguiría siendo una violencia epistémica el ocultamiento de la persistencia cultural gitana en esa realidad (Castaño, 2015).

9. Antonio Ortega es periodista sevillano y crítico de flamenco. Este fragmento está sacado del programa "Flamencos y Cronopios", emitido por 8tv Andalucía, el día 15 de mayo de 2015, y que él mismo presenta y dirige. 


\subsection{Oralidad, sonido y memoria. A los márgenes de la estética y la racionalidad de las músicas occidentales}

Como venimos comentando a lo largo de esta conversación, escasos son los estudios que se han dedicado a explorar la dimensión oral de las producciones realizadas por grupos no hegemónicos. En este caso, el flamenco(s) no es una excepción. El análisis de las letras, el estudio de la lírica flamenca: sus formas poéticas, su estructura compositiva, y los temas recurrentes, no son suficiente para acercarnos al ser y sentir flamenco. Creemos que esta es una forma escritocéntrica de abordar una aproximación a la pluralidad de formas expresivas que se resuelven, en mayor medida, en el plano de la oralidad y la transmisión directa. Creemos también que no es casualidad que esto sea así. La escritura es un "artefacto colonial" (Gimeno y Castaño, 2014) capaz de fijar en imágenes los sonidos, es un producto colonial capaz de deslindar de la comunicación otros aspectos centrales como los gestuales-corporales, los olores, los sabores y el tacto, posicionando la mirada como medio para comprender, conocer y pensar los fenómenos: "aunque las palabras están fundadas en el habla oral, la escritura las encierra titánicamente en un campo visual" (Ong, 2002: 21). Es por ello, que la diversidad inasible e inconmensurable de significados producidos en los procesos orales de transmisión "no resulta ser legítima en el espacio homogéneo" (Palermo, 2006: 32).

Esta no legitimidad, arrogada por quienes tienen la capacidad de definir y legitimar -o no- qué es o no conocimiento, qué es o no es arte, qué es o no es estético, válido o científico, no es un asunto nuevo. Uno de los trabajos más citado en este campo es el realizado por Walter Jackson Ong (1982), que establece un estudio comparativo entre oralidad y escritura, resolviendo que "el conocimiento de esta última es absolutamente necesaria para el desarrollo no sólo de la ciencia, sino también de la historia, la filosofía, la interpretación explicativa de la literatura y de todo arte", ya que "ante la ausencia de categorías analíticas complejas [...] la cultura oral se preocupa poco por conservar el conocimiento de las artes como un cuerpo autosuficiente y abstracto" (Ong, 2002: 48-49). Esto implica la minusvaloración de aquellas sociedades y colectivos cuyos procesos de expresión y conocimiento para la reproducción y autorrepresentación son sobre todo producidos en el plano de la oralidad. Supone una colonización de la memoria, de los sentidos, y de las expresiones artísticas de estos colectivos: los cuáles, según Ong, estarían en una posición inferior respecto a aquellas sociedades y grupos que producen conocimiento (y arte) a través de formas visuales e impresas. Seríamos, por tanto, menores de edad incapaces de crear, pensar y producir nociones complejas. Éstas corresponden a las sociedades escritocéntricas, científicas, eurocentradas y racionales.

En el caso del flamenco(s), entendido como epistemología del sentir situada, cuyo cuerpo de saberes y conocimientos vernáculos se transmiten fundamentalmente de manera hablada, cantada, bailada y escuchada, éste se posiciona frente a los epistemicidios y 
musicidios que suponen pensar(lo) en su dimensión únicamente estética, musical y escrito-visual. Los intentos por recoger nuestras músicas en pentagramas, en escribirla al modo occidental, no ha producido ningún resultado (Cruces, 2002; Peña, 2013). No ha sido posible el intento de sujeción y fijación de unas expresiones que hasta bien avanzado el siglo XX seguían siendo transmitidas y aprendidas desde la oralidad, y que "hoy día, incluso viviendo en una sociedad escritocentrista, debemos pensar el cante flamenco desde la perspectiva de la oralidad: ya que su forma de recepción es el oído y su soporte la memoria" (Sánchez, 2004: 48-49). De manera más explícita lo expresaba no hace mucho el tocaor y cantaor sevillano, Rubén Rubio: "aquí la partitura no te vale pa ná, no se toca con patrones" 10 .

Es por tanto, esta conversación: aproximarnos a las formas flamencas como epistemología del sentir situada, un ejercicio de "aesthesis decolonial" (Mignolo, 2010; Tlostonova, $2011)^{11}$ frente a la concepción de arte como lo bello y lo sublime, separado de la subjetividad y de sus mecanismos de percepción, sentido y emoción:

"Hoy en vez de decir, „hija qué mal te colocas! se habla de la estética ¿pero eso qué es, eso de la estética qué es, si el flamenco ha sido siempre mu bruto, salvaje, una piedra sin pulí?, y ahora que si la estética [...]" (Dolores Montoya, "La Farruca”, 2015) ${ }^{12}$.

"cuando un gitano flamenco canta o baila, conforme a la herencia musical de sus mayores, su objetivo no es el de conseguir una expresión bella y armoniosa, ya que nuestros cantes y nuestros bailes son para ser sentidos interiormente y manifestarlos desde el dolor enquistado en lo más profundo del alma [...], esos mismos cantes, aunque estén técnicamente bien interpretados, serán cantes muy fríos y momificados [...]. Los cantes de los gitanos flamencos los preside, eminentemente, el sentimiento trágico o dramático. Nunca se magnifica en ellos el sentido estético, ni como soporte, ni como finalidad” (Pedro Peña, 2013: 115,145)

10. Extracto de entrevista realizada el 18 de diciembre de 2015.

11. De acuerdo con Mignolo (2010) y Tlostonova (2011), la aesthesis en su concepción griega originaria, y que ha llegado hasta hoy, "giraba en torno a vocablos como sensación, proceso de percepción, sensación visual, sensación gustativa, sensación auditiva” hasta que a partir del siglo XVII, fundamentalmente con la obra de Immanuel Kant, "el concepto se restringe pasando a significar sensación de lo bello. Nace así la estética como teoría particular de tales sensaciones relacionadas con la belleza, y el concepto de arte como práctica" (Mignolo, 2010, 13-14): autónoma y desligada de su proceso vivo. "No fue otra que la estética europea de la modernidad laica la que colonizó la aesthesis (la habilidad de percibir a través de los sentidos) como parte de su colonización global del ser y del conocimiento, llevando a formulaciones estrictas de lo que es bello y sublime" (Tlostonova, 2011: 15).

12. Entrevista realizada por Antonio Ortega, en el programa "Flamencos y Cronopios", el 15 de mayo de 2015. 
Es en este sentido(s), que el flamenco(s) del que venimos hablando descentra la vista y la mirada. No la necesita. Es el oído, sobre todo, quien conecta las expresiones con la memoria (experiencias y vivencias). Saber escuchar, saber sentir, decir el cante, escuchar el cante, son expresiones y aspectos relevantes de las epistemologías del sentir flamencas, de los conocimientos y expresiones musicales vernáculas que la componen. De esta manera, es en sí misma un acto y proceso de aesthesis decolonial, en tanto que descentra el ojo para comunicar y sentir: la vista no es que no sea necesaria, es que molesta e interrumpe la conexión del sonido con la memoria y el ritmo (compás), con los recuerdos, con la creatividad y la improvisación:

"cierro los ojos porque los ojos no me sirven pa cantar. Los ojos no me sirven para nada en ese momento, entonces se sueña mejor con los ojos cerrados, y como yo soy un soñador pues cierro los ojos” (Manuel Molina Fernández, 2015) ${ }^{13}$.

"cierras los ojos y al final pierdes la mirá, así te escuchas mejor, escuchas mejor la guitarra, las palmas, un compás, tú cierras los ojos y te metes ahí, es como que vas viajando en eso, escuchando el ritmo" (Rubén Rubio, 2015) ${ }^{14}$.

El compás, el ritmo, no son el resultado de operaciones matemáticas ni racionales, sino que conecta los sentidos y las emociones con la música y lo que se canta. Es así que los procesos de aprendizaje basados en la oralidad utilizan la memoria rítmica como forma de aprendizaje de las letras, y no al revés, es decir, no se estudian las letras delante de un papel y luego se meten por bulerías, soleá o siguiriya, sino que fluye en sentido contrario, es el compás aprendido el que recuerda lo que se va a decir cantando

"Al final no es otra cosa que tener desarrollaos ciertos sentidos pa poder escuchar. Ahora viene un japonés y aprende, le da el metrónomo, es una calculadora pero no le da el feeling, no tiene ese compás. Eso es una cadencia, un tipo de caerse, ¿es caerse no primo? Es una forma de quedarse atrás" (Rubén Rubio, 2015) ${ }^{15}$.

Es así que, para la transmisión y aprendizaje de las formas expresivas flamencas, se requiere la presencia fusionada (no articuladas, ya que son inseparables por sí mismas) de tres procesos: oralidad, sonido y memoria. Ellas dan cuerpo a la transmisión sin necesidad de la fijación de la lectoescritura, son ellas las que definen la singularidad de nuestras músicas y cosmovisiones acompañándonos en cada momento de la vida. Sean o no expresadas musicalmente, son inseparables de las experiencias cotidianas y

13. Entrevista realizada por Antonio Ortega, en el programa "Flamencos y Cronopios", el 08 de mayo de 2015.

14. Extracto de entrevista realizada el 18 de diciembre de 2015.

15. Fragmento de la historia de vida realizada junto a Rubén Rubio, 23 de septiembre de 2015. 
personales. Es esta memoria sonora-vivencial la que permite, como señalaba el cantaor José el de la Tomasa "que la siguiriya no salga seca". O como se pronunciaba al respecto Enrique Morente, en una entrevista realizada a ElPaís.com en el año 2005, "las letras son sólo un clavo donde colgar la expresión" ${ }^{16}$. Es por ello, que en el flamenco(s) la letra se pone al servicio "no sólo de la combinación específica de la melodía, armonía y compás, sino también de la expresividad. [...] El cante se ejecuta de modo aleatorio según la actuación conjunta de la memoria y la voluntad, como procedimiento mnemotécnico a través de la que el ejecutante lee mentalmente la música que canta" (Cristina Cruces, 2002: 124-126) ${ }^{17}$. Sobre este tema son interesantes las aportaciones de Antonio Mandly (2010, 2013), en tanto que la fusión oralidad, sonido, memoria, es definida como "memoria hiponoética: memoria de aprendizaje rítmico, auditiva, oral, inasible, inconcebible, que tiene la virtualidad de dilatar o acortar los tiempos cuando uno se sumerge en ellos" (Mandly y Llorente, 2013). Este recurso a la memoria rítmica se pondría en relación con "determinados sonidos, que son sentidos como propios y que están ritualizados como toporitmos tempo-sensitivos de identidad" (García Calvo 1983: 8-14, en Mandly, 2010: 97): los "topo-ritmos" refieren, en lenguaje más sencillo, a aquellos cantes que se identifican con una adscripción local o personal (Soleares de Jerez, de Triana, de Cádiz, de Utrera, de Lebrija; o Soleares de Merced la Serneta, de Joaquín el de la Paula, de María La Andonda, o la siguiriya de Manuel Torre y Paco la Luz, por poner algunos ejemplos). Y "temposensitividad" señalaría la memoria y los recuerdos de lugares, olores, sabores, fechas señaladas, vivencias; "por qué me dice a mí la gente/que eran los días señalaíto de Santiago y Santa Ana [...]", "a clavito y a canela, me hueles tú a mí, la que no huele a clavito y a canela, no sabe (d)istinguí [...]" - ambas por siguiriya-.

Esta memoria rítmica, secuencial, sentido-compartida, junto a otros recursos: deformación de los significantes a través del ritmo, melismas e implicaturas ${ }^{18}$, refuerzan

16. Entrevista de Miguel Mora a Enrique Morente para ElPaís.com. 09 de octubre de 2005.

17. Esto es uno de los elementos (no el único) que hace tan reconocible y diferente a las formas musicales flamencas de las músicas occidentales. En terminología musical, el elemento central de esta diferencia reside en que son microtonales, es decir "trabaja con intervalos inferiores al medio tono, como otras músicas orientales" (Cruces, 2002: 136), o de manera más detallada, "la división de los tonos en cuatro o más partes, en vez de en dos, como es habitual en occidente. El sistema actual está concebido para cifrar la división de los tonos sólo en dos partes, sostenidos o bemoles, mientras que el verdadero cante de los gitanos flamencos puede fluir por microtonalidades" (Peña, 2013: 119).

18. "Un melisma es una sucesión de notas musicales sobre una misma sílaba literaria" (Cruces, 2002: 136), es decir, el ritmo, el compás para que esté cuadrao necesita alargar unas sílabas y acortar otras, o bien contraer las palabras para que la letra entre/esté a compás. Las implicaturas refieren a que en el remate de un cante no se termina cantando la letra, siendo habitualmente sustituido por un "ejeeeeeeee", o por el silencio. 
el aprendizaje y la comunicación ampliando la diversidad expresivo-creativa sobre un mismo ritmo/compás, a la vez que promueve la improvisación haciendo que "cada cante sea irrepetible, como es intransferible el timbre de la voz o la dosificación personal del silencio" (Molina y Mairena, 1991: 78).

Es en relación a la fusión de oralidad, sonido y memoria: a la memoria rítmica y las vivencias, a las ducas/duquelas (fatigas, penas) expresadas a compás, que es posible detectar un elemento comunicativo que está fuera de toda lógica occidental, racional-moderna o científica: el duende. Sobre este momento expresivo-comunicativo no caben definiciones cerradas ni categoriales, todo lo más exposiciones circulares a las que el lenguaje escrito no se acerca o lo intenta con una prosa excesivamente poética, rimbombante y nada sencilla, que no hace otra cosa que despistar: léase a Federico García Lorca (1933). El duende no se define, ni puede ser definido por el lenguaje racional, se expresa, se vive, se experimenta. Hay que cerrar los ojos, la vista no sirve para comunicar con él (ella), no sirven los metrónomos, los técnicos de sonido, los ensayos, o cantar bien. El duende es otra cosa, algo así como un momento de totalidad expresiva, una especie de catarsis comunicativa anclada en los ritmos de la memoria sazonada con inspiración:

"Yo eso no sé explicarlo. Eso es como cuando una noche estás mu bien y te sale to. Y con los que estás en frente estás en comunión con ellos. Y no sé, no te das cuenta, te das cuenta después cuando lo piensas. O sea, el duende es algo que sale sin pensar, como lo pienses no sale. Cuando estás tú a gusto. Pa mi es eso, es que no se puede ni explicar. En el duende va todo junto, tiene que ir todo junto. En verdad, en ese momento, no estoy pensando en na. Pa mi el duende es eso, que cuando viene viene, es la inspiración, y unío con el compás, unío con el ambiente, y cuando nadie te estorba, porque eso es muy importante, cuando nadie te estorba. Primo, pa mi el duende es la inspiración, como la musa que se te ha aparecío y no se quiere ir de ti en un ratito. Y eso no se puede escribir con un boli en un papel, porque no sale igual, si lo tienes grabao tampoco lo vas a reproducir igual que antes por mucho que lo entrenes. El duende es la inspiración, algo que te llega" (Rubén Rubio, 2015).

El duende, que podría poner en conversación otros procesos similares como el trance para otras formas músico-orales no occidentales, no pone en juego o no expresa cantar bien o mal, sino que "lo que está en juego cuando fluye esa forma de cantar, es algo mucho más trascendente como es la autenticidad, o lo que es lo mismo: el ser o el no ser" (Pedro Peña, 2013: 145).

\subsection{Procesos ligados a Grandes Traumas colectivos y personales}

Y ese ser del cante al que alude Pedro Peña, de "gruta oscura", de "sonidos negros", de "cantes desgarrados", tiene poco misterio que descubrir, y sí mucho de emergencia ante la profusión de los silencios que, esconden tanto como muestran. Los silencios, tal como los define Boaventura de Sousa Santos (2011: 123) corresponden "no a lo impronunciable, 
sino a los diferentes ritmos con que los distintos saberes y prácticas sociales articulan las palabras con los silencios". Estos silencios, en el flamenco(s), también han de ir a compás, toda expresión ha de ir a compás.

Silencio, sonido y memoria, en este caso, también aparecen fusionados en las epistemologías del sentir flamencas. Es lo que Mayra Estévez Trujillo (2015) denomina "generación sonora", es decir, "la articulación entre sonido/silencio/sonido", concepto que utiliza para denunciar la colonialidad de los sonidos (cabría aquí hablar de las expresiones descontextualizadas, folklorizadas, exotizadas, y des-identificadas de sus entornos de uso, así como las sonoridades impuestas por las grandes discográficas y los mass media), de los sentidos y las emociones, ante la supremacía y deficiencias de la vista para (re) conocer las producciones artísticas no coloniales: "el sonido [y los silencios] llega a lugares a los que la vista no puede. El sonido se zambulle por debajo de la superficie. El sonido penetra hasta el corazón de las cosas [y las personas]. Si dejo de tener en cuenta las cosas a las cuales el sonido está ligado, el mundo fenomenológico desaparece" (Estévez, 2015: 58).

Esta colonialidad del sonido, añadimos nosotros, es también una colonialidad de los silencios. Ambos se relacionan con lo que hemos denominado Grandes Traumas ${ }^{19}$. Esto es, la ligazón entre procesos vivenciales personales y colectivos impresos en los recuerdos de cada uno/a. Cantado por bulerías por la lebrijana Inés Bacán, y con ese sentido metafórico que define a las letras flamencas (Lizcano, 2006; García Olivares, 2003), sonaría así: "ya sé que no es por compás/ya sé que no es por compás/mira si mi pena es grande/que no se pudo ocultar"; o expresado por el primo Ruben Rubio (2015), "El flamenco es una música especial que sale de dentro, que no puedes hacerla sin haber sufrío, tienes que tener tu espinita. Es algo que contra más has sufrío mejor cantas, que como tengas una vida cómoda no sale bien eso"; o expresado por Rosario Montoya "La Farruca" (2015):

"pa bailá de verdad hay que pasar fatiga [...] ¿quieres más argumento, Antonio, que te estoy contando que tienes un libro ahí?. Tienes un libro, donde está blanco pero lo estás leyendo. Cuando salimos damos nuestra vida, que no es de mentira, ahí estamos echando reaños y apretando riñones y estómago pa dentro que cuando llegamos al camerino se nos sale el hígado por la boca"

Y si no se puede deslindar, incluso, de una actuación en un escenario, imagínense para un acontecimiento que marca la vida de las personas como es el fallecimiento de una mare, un pare o un hijo (bata, bato, chavó, en caló). Emotiva es, por citar un caso, la

19. Agradezco los aportes en los debates y reflexiones del equipo de trabajo de doctorandos de la profesora Dra. Ángeles Castaño, sobre la memoria, las violencias y la colonialidad. Agradezco a María Paula Meneses los debates, que sobre estas cuestiones, mantuvimos durante la estancia de investigación que desarrollé en el Centro de Estudios Sociales de Coímbra en 2015. 
experiencia que cuenta el tocaor y cantaor Pedro Peña tras el fallecimiento de su bata María Fernández "La Perrata", tras el cual, tanto él como su hermano (Juan Peña "El Lebrijano") le cantaron por siguiriya en su tumba y terminaron abrazados llorando. $\mathrm{O}$, en mi caso, la imposibilidad de decir ciertos cantes que me recuerdan a mi bato (fallecido ahora hace casi dos años) porque se me rompe la voz y no puedo continuar: por bulerías, "lavaba la chacha mía/ lavaba la chacha mía/ contri más lavaba lavaba/ la baba se me/le caía"; o las soleares de Joaquín el de la Paula, "dicen que tú no me quieres/pena yo no tengo ninguna...", o la soleá de Charamusco: "subí a una alta montaña/a buscar leña pal fuego/ como no la encontraba...", por martinete: "Ya no soy aquel que fuera-era/ni quien debía de ser/...", y así podríamos seguir. Los ejemplos, para todos los casos similares acontecidos a flamencos y flamencas, tendrían voces, contenidos, y formas de expresar, sentir y emocionarse, seguramente muy parecidas. El dolor se alivia cantando entre silencios.

Por otro lado, y unido a las vivencias directas y personales, los grandes traumas referirían también y en buena medida, a procesos de subalternidad, persecución y etnocidio. Y no fue ni es un hecho aislado, "ni es de ley" comparar procesos denigrantes entre colectivos subalternizados como hacen algunos(as): ¿cómo pueden atreverse éstos a medir el sufrimiento de gitanos, moriscos y sefardíes? ¿Cómo se mide el dolor, la angustia, el castigo infringido durante siglos? Hay que ser muy atrevido y/o interesado para realizar este tipo de operaciones "matemáticas", sobre todo cuando hablamos de personas y de procesos incalificables e inmedibles por la angustia, el sufrimiento y el dolor humano que provocaron. En España, y para el caso de los y las gitanas, las normativas dictadas para la erradicación de sus costumbres, vestimentas, libre circulación e idioma (caló/ romané) comienzan con la primera Pragmática promulgada por los Reyes Católicos en 1499 en Medina del Campo (Valladolid), hasta la última ley anti-gitanos del régimen franquista (presente en el Reglamento de la Guardia Civil vigente en ese momento) derogada en 1978 (Arrebola, 2011; San Román, 1997; Gamella et al., 2011) ${ }^{20}$. Son cinco siglos najando (huyendo), que han dejado no sólo un poso de sentimiento trágico y desgarrado detectable en las letras de los cantes, sino que además, y por los cuales, se han constituido y asentado muchos de los prejuicios y representaciones estereotipadas adscritas a un supuesto colectivo gitano homogéneo.

Recogemos un testimonio cantado que muestra hasta qué punto emergen de una u otra forma al decir el cante. Del disco "Persecución" (1976), mostramos fragmentos de tientos ("No le temblaron las manos") y romances (“Mando que en 60 días"): canta Juan Peña "El Lebrijano", toca Pedro Peña, letras del poeta Félix Grande. Aunque extenso, creemos que merece la pena escuchar:

20. Pedro Peña (2013: 109), recoge que se dictaron "280 órdenes, concejos, pragmáticas y leyes similares dictadas contra los gitanos" durante este periodo. 
"No fueron los judíos ni los moros/ fueron los reyes cristianos/Ella se llamó Isabel, el se llamaba Fernando./Cuando firmaron la Ley no les tembló tembló las manos./Finales del siglo XV/noventainueve era el año/una ley sin compasión nace en Medina del Campo./Cuando firmó firmó la ley no les tembló tembló las manos/“Finales del siglo XV, noventainueve era el año/toda España nos persigue desde Medina del Campo./Najaremos muchos siglos/siglos de sangre y de espanto/Najaremos muchos siglos pa seguir siendo gitanos. /La memoria, la memoria era una casa cerraíta a cal y canto/por dentro está el siglo XV, por fuera Medina del Campo/Cuando firmó firmó la Ley, no les tembló tembló las manos” (Juan Peña, "El Lebrijano", "Persecución", Tientos)

"Majestades, majestades/ doña Isabel y don Fernando/antes de poner la firma, pensadlo, por Dios pensadlo./Mando que si no obedecen se les den 100 latigazos/y con sangre en la espaldas de renglón sean desterraos./Y por la segunda vez, con cuchillos afilaos les corten las orejas/y vuelvan otra vez a ser desterraos./Y por la tercera vez, si no cumplen lo mandao/ que le apresen y que sean por toa la vía ya esclavos" (Juan Peña, "El Lebrijano", "Persecución”, Romance)

Las marcas culturales heredadas, las marcas de la subalternidad, si no son visibles por uno mismo te las hacen recordar: por poner sólo un ejemplo, recuerdo, en un viaje a Mallorca que hice con 14 años, cómo dos chicos madrileños me gritaron: igitano, que sólo servís para coger lechugas! Esto, que podría ser una anécdota, no lo es, y se expresa tanto en las formas de ser y sentir flamenco, como en las expresiones musicales que nos identifican. Los sonidos de sus/nuestras músicas, y los silencios de "casa para adentro y de casa para afuera" (Walsh y García Salazar, 2015), han ido indisolublemente unidos a las experiencias personales y al trauma colectivo de los y las gitanas en España, y eso se nota al cantar, al bailar, al hablar, al sentir, al emocionarse(nos), y al expresarse(nos): son cinco siglos (y esperemos que no sean cinco más) ¿cómo no se va a notar? ¿Cómo, si no, y de dónde, y qué expresan los cantes de galeras, las carceleras, y otras como las toná, la debla, o el martinete, si uno atiende a sus letras y sobre todo a sus formas expresivas?.

Si bien en la actualidad, sobre todo en Andalucía, y en enclaves concretos como Triana, Jerez, Lebrija, Utrera, y otros, los procesos de convivencia, las parejas mixtas, y las políticas de promoción del flamenco como un recurso cultural de consumo, han posibilitado unas condiciones de existencia que, aun no siendo de pleno (re)conocimiento de las diversas formas de ser, sentir y expresar gitano-andaluzas en el conjunto de la sociedad y grupos mayoritarios, no son ni de lejos ni de cerca las aludidas para estos cinco siglos atrás.

\subsection{Autorepresentación y resistencias. Estrategias, antídotos y conversaciones musicales inter-saberes}

Las epistemologías musicales flamencas suponen hablar de uno mismo desde uno mismo y con otros, de cómo sentimos y expresamos desde/en/el mundo. En ellas confluyen 
elementos, dinámicas y narrativas de identidad y (auto)representación situadas frente a las presiones homogeneizadoras y totalizadoras de la modernidad globalizada, el estado nación y las políticas de patrimonialización locales (Castaño y Hernández, 2014): suponen la continuidad del grupo, de la memoria, de sus conocimientos y formas de ser sintiendo. Y por esto mismo, se configuran (unas veces narradas y musicadas de manera consciente, otras inconscientemente) como alternativas a procesos de colonialidad interna y externa.

Si pensamos el flamenco(s) como un "lenguaje especializado" (Gamella, 2011; Lizcano, 2006; Olivares, 2003) más allá de sus aspectos formales: aliteraciones, sentido metafórico, uso de los diminutivos, contracciones de palabras, uso de la primera persona del singular para referirse a uno mismo, de la segunda para hablar del amor/desamor, y de la tercera para referir a Dios y la Naturaleza (Molina y Mairena, 1971), nos encontramos además con el uso frecuente de términos, vocablos y expresiones en caló. Y esta presencia, en sí misma, es un valor inmaterial/material de las epistemologías del sentir flamenca(s) al tener presente y activar la memoria colectiva y el sentido de pertenencia, al menos, desde dos formas. Una, expresándola a través de las letras del cante flamenco, donde sin necesidad de cuantificar sabemos que su presencia es cualitativa, continuada y relevante. Dos, el caló es utilizado en la cotidianeidad, en la vida diaria, en momentos y entornos concretos relacionados y ligados a lo identitario, al reconocimiento mutuo entre primos/ primas. Durante lo que llevamos de conversación, por ejemplo, hemos utilizado algunas como caló, rumí/romí, chavó/chavorrillo, ducas/duquelas, bato/bata, najar. Es decir, si lo cualitativo es relevante, el caló es utilizado por un colectivo que le confiere sentido, y a su vez, esa comunidad le da sentido al caló en tanto que es parte integrante de sus formas de expresión, de su proceso vivo ${ }^{21}$. Y esto, entendemos, es un recurso a la memoria y un antídoto frente a los silencios de la colonialidad: un patrimonio inmaterial vernáculo frente a las "lenguas gringo-europeas erigidas como las únicas lenguas de conocimiento y para la producción de los discursos de verdad científicos" (Guerrero Arias, 2010: 86).

Otro aspecto relevante, y creemos central, si atendemos a las voces que vienen participando en esta conversación, es que las narrativas y expresiones musicales flamencas, en sus contextos vernáculos de producción, centran su interés en el ser humano: "al referirnos al cante, en general aludimos a su significación más humana que estética” (Molina y Mairena, 1971: 99). Ya lo dice la soleá "pa qué quiero los dineros/si no me sirven pa ná/salud es lo que yo quiero/y no la pueo comprá".

21. Bien es cierto, que las distintas Pragmáticas, órdenes reales y demás normativas contra gitanos, acontecidas desde el siglo XV hasta el siglo XVIII, y las posteriores políticas asimilacionista de la transición española y el gobierno autonómico, han respondido a su cometido: el silenciamiento y casi total olvido de uno de los elementos relevantes de la cosmovisión de los colectivos, sus formas de hablar. Esto es irrefutable. Sin embargo, no menos cierto es que se sigue utilizando por una comunidad que le confiere sentido mediante sus formas expresivas musicales y cotidianas. 
Con respecto al sentido de la vida y las relaciones, esto se dice:

"El dinero es un veneno malo, es lo peor que pueda existir en esta tierra. [...]. La crisis que estamos sufriendo es la incomprensión, el egoísmo, el poder, todo eso es cancerígeno, la metástasis: el dinero es el cáncer y todo eso que te estoy diciendo es la metástasis. El dinero es pa gastárselo y pa regalarlo [...], eso es lo más hermoso que puede hacer el dinero, pa eso sirve el dinero. Y pa darle mucho gusto a tu familia y a tus niños, y a los niños de los demás también, no pa guardarlo ni pa contarlo [...]. El tiempo se va y hay que ser inteligente y sabértelo gastar, y procurar de arrepentirte lo menos posible, hacer las cosas que tú quieras hacer, no hacerle daño a nadie y hacer lo que te dé la gana siempre que puedas" (Manuel Molina, 2015).

“La envidia es un cante que no va a compás” (José el de la Tomasa, 2015).

"yo voy a contracorriente, siempre. Yo tengo mi mundo sola: como cuando me da la gana, me acuesto cuando tengo sueño" (Encarnación Amador, "La Susi”, 2015)22.

“no veo la tele, que veo algún detalle y digo, pero esto qué es, ¿dónde están los gitanos? ¿qué somos gitanos por dinero?, cuando los gitanos no hemos tenido dinero nos hemos ido a coger melocotones. Y ahora por tener dinero, por ganar dinero, dos pesetas porque son dos tristes pesetas, presentan tantas porquerías en la televisión los gitanos, ¿dónde se ha visto eso?" (La Farruca, 2015).

Las relaciones interpersonales, directas, no son mercadeables. El espacio racional moderno no tiene herramientas para medir las expresiones del ser y sentir flamenco(s), tiempo y luces no siempre son coincidentes con "comer cuando se quiere" o "dormir de día, estar despierto de noche”. Esto rompe la concepción del espacio euclidiano: las líneas pueden o no tocarse, eso no es lo relevante desde las epistemologías del sentir flamenca(s), lo fundamental es de qué manera yo me puedo desplazar por ellas sin perder el rumbo, el compás. Todo ha de ir a compás. Y el compás del flamenco(s) no es el de la racionalidad posmoderna: su tiempo y espacio están en relación directa con las vivencias y experiencias, con la memoria rítmica, con el ritmo socializante y socializador producido en contextos específicos, con el ser humano (la familia, el encuentro interfamiliar y comunitario, con los amigos, con otros músicos, con quien quiera y sepa escuchar), y no tanto con las calculadoras, los metrónomos, las partituras y los pentagramas. En esto, además, las narrativas son coincidentes, se canta más a gusto en familia, en la calle, en las peñas o los bares, en una plaza, en una boda o encuentro familiar, que en un escenario o en un estudio de grabación.

Con respecto al flamenco(s) que no se produce en sus entornos vernáculos:

22. Entrevista realizada por Antonio Ortega, en el programa "Flamencos y Cronopios", el 22 de mayo de 2015. 
"Si tú al final cantas con alguien que no tiene compás lo pierde hasta tú, ¡qué no! Cuando tú lo tienes dentro y sabes cuando tienes que partir, donde tienes que romper, donde te tienes que llevar, donde vas a descansar...y eso es tan natural aquí. [...] He estao en una escuela de flamenco en Austria pero aquello no es flamenco, tengo por ahí los vídeos para que te eches las manos a la cabeza. Y te lo venden como flamenco, entonces tú sabes" (Rubén Rubio, 2015).

"Todo está en manos de los arreglistas que van cuadriculados. [...]. El otro día estuve en un estudio de grabación y me siento y digo oye eso está desafinao y dice el ingeniero no te preocupe eso lo arreglo yo: ¿desafinao y lo va a arreglar tú?, me pregunto pa mí, oye que esto está descuadrao... y bueno cojo me levanto y digo me voy, y me dicen pero Manuel por qué te va, y dije: aquí cuándo se dice ;ole! [...] eso no lo puede arreglar una máquina, eso no es humano...y la cosa está asî" (Manuel Molina, 2015).

Para concluir esta conversación, en el marco de la cual hemos querido presentar las epistemologías del sentir flamenca(s), no queremos dejar de señalar cómo todo este conjunto de saberes y conocimientos vernáculos se sitúan no sólo como contextos comunicativos específicos para la reproducción colectiva, sino que, además, frente a la modernidad se sitúan como estrategias que permiten: uno, activar procesos de movilidad social y/o mejora de las condiciones de vida; dos, capacidad para conversar con otras cosmovisiones musicales; tres, se posicionan como antídoto para enfrentar las tensiones de la modernidad.

Para la primera de ellas, el conocimiento de un patrimonio específico como el flamenco(s) acaba siendo apreciado al tener tanto un valor cultural como de mercado. De esta manera, la yuxtaposición de lo local con lo estatal-global, el contacto de lo periférico con lo central, y lo hegemónico con lo subalterno, se han convertido no sólo en "potentes activos de la economía cultural" (Barriendos, 2007: 166) sino que además, han posibilitado a los miembros y familias gitanas flamenco-andaluzas acceder a una mejora en sus condiciones de vida. De esta manera, aquellos que consiguen acceder a canales formales de difusión y contratación son reconocidos dentro de su propio grupo, ya que los miembros más cercanos suelen vivir alrededor de la persona-artista, provocando incluso un cambio de estatus dentro de la familia y la comunidad. A su vez, es considerado un valor por el grupo mayoritario y las lógicas neoliberales de consumo cultural. Los ejemplos son diversos y variados, entendiendo no sólo a aquellas personas consagradas sino también a aquellos flamencos cuyo "saber-hacer" (Palermo, 2009) les ha permitido ganarse la vida y mandar en su hambre.

Para el segundo caso, las heridas abiertas y las marcas inscritas por la modernidad/ colonialidad en las distintas periferias del mundo, sobre los grupos y colectivos situados a los márgenes del proyecto modernizador, permite articular encuentros entre músicas con 
memorias rítmico-sonoras singulares: el caso de Juan Peña "El Lebrijano" y la Orquesta Andalusí de Tánger (Marruecos), o José Fernández Torres “Tomatito" con la música sufí de Omar Faruk, de Raimundo Amador con BB King, o el cante de Sandra Carrasco conversando con el sitar de Anoushka Shankar, serían algunos ejemplos significativos y reconocibles.

En tercer lugar, y para concluir, las formas musicales flamencas, en tanto que parte inseparable de nuestras formas de ser y sentir, consiguen paliar las dificultades cotidianas en momentos concretos de sensación y emoción extrema

"Como madre y persona, cuando yo lo veo bailar [se refiere a su hijo Farruquito] se para el tiempo, me cuenta historias, leo, respiro, veo todo. Es una cosa que no la puedo explicar pero sí la siento. Es como resucitar, como una vida nueva. [...]. "Lo que me alivia es mi baile, pero penas tengo muchas" (La Farruca, 2015).

"Yo cuando estoy con el público me transporto a mí misma, a mi mundo. Entonces como yo me transporto a otra vida, cuando canto tengo ilusiones, me vienen las ilusiones, me viene las ganas de vivir" ("La Susi", 2015).

"Las bulerías son vitaminas, una bulería bien cantá es vitamina. Yo canto para ahorrarme en psicólogos” (Rubén Rubio, 2015).

\section{SIENTO Y SOY, LUEGO EXISTO}

"El que dice ay ay ay/ (es) señá que la dolío/pobre der corazón mío/por qué me lo martratái/ ay ay ay" (Familia Montoya, por bulerías)

Gracias si llegaron hasta aquí. Leer un texto que está escrito para ser contado y cantado entendemos que no es tarea fácil. Volvemos a reiterar que este no es un texto para ser leído en su literalidad, así que haber participado de ese saber-escuchar, saber-sentir, sentir-sentir, emocionarse-emocionarse, compartir-compartir, con las voces que aquí hemos intervenido, puede ser considerado un gesto de flamenquería, memoria y justicia cognitiva ${ }^{23}$. Esta conversación no ha tenido más interés que sumar voces a la posibilidad de pensar en una epistemología del sentir situada que se expresa fundamentalmente cantando y bailando. Y por otro lado, tomar parte de eso que Boaventura de Sousa Santos denomina (2011) "cosmopolitismo oposicional subalterno", motivado por la resistencia a asumir de manera pasiva la deshumanización, las desigualdades, los silenciamientos y olvidos deliberados de la modernidad/colonialidad; promoviendo las emergencias

23. Este concepto es autoría de la Dra. María Paula Meneses (CES), y en este texto está tomado de las conferencias que dio en el Departamento de Antropología de la Universidad de Sevilla como profesora invitada en el Máster de Antropología perteneciente a dicho Departamento, en abril de 2015. 
y las posibilidades de conversar con otras cosmovisiones situadas en la periferia del neoliberalismo global.

Además de incluir las experiencias y vivencias en la producción y narración de los conocimientos, saberes, y epistemologías: entendiendo que de los sentidos proceden las percepciones que captan el mundo, sus filtros, y las formas de interpretar, comprender y expresar tanto las relaciones individuales y grupales como el contexto en el que éstas se resuelven. Las epistemologías han de hablar de un proceso vivo, sentido y situado. Sin sentidos no hay conocimientos, ni episteme, sería cuestionable incluso hablar de conocimiento situado en/desde/de los seres humanos. Es este, y desde aquí, un acto y proceso de aesthesis decolonial. Hágase la subjetividad, se abra la abstracción, y caiga junto a la inconmensurabilidad de las memorias no narradas.

Es así como nos conocimos el primo Rubén y yo, "buskando el duende", y no tanto por encontrarlo sino porque nos habíamos encontrado. Es así que, y aunque aquí no aparecen en el papel, están en este texto por su participación y ayuda en la investigación doctoral en curso: los Zurita, “El juanan”, Inma Rivero, Rafael Fajardo, mi primo Javi, y tantos y tantas. Es así como Sebastián Peña "Bacán" me ha abierto las puertas de la sabiduría (y de su casa) flamenca y gitana que atesora su familia: como hemos comentado, una de las más relevantes y extensas del flamenco, y por tanto protagonistas de todo lo que aquí venimos contando. Es así como conocí a (mi) rumí Karmen. Es así como, tras días sin comer y estar fuera de Andalucía sin na de na, uno decide activar ese patrimonio inmaterial que ha aprendido de pequeño: "Estábamos en Gijón, eran aproximadamente las diez de la noche y el estómago hacía compás por bulería ¡qué hambre teníamos los cuatro! (prima Pop, primo Pol, Karmen y yo). Salimos de una plaza donde habíamos estado cantando con un chico argentino (Jandro) que hacía muy bien los tangos de su tierra, después de bebernos no sé cuántas botellas de sidra. Ni un euro, no teníamos ni un euro, así que nos fuimos a la zona de bares y restaurantes, en el paseo marítimo (era julio o agosto). Antes habíamos cogido una silla de cualquiera sabe dónde ni cómo (había sido la prima Pop, que pa eso tiene un arte): en ella me senté, detrás se pusieron la Pop, el Pol y mi rumí haciendo compás, y así fueron saliendo las letras en sus cantes (por bulerías, soleá y martinete, que van mejor "ar gorpe”), y así nos echaron lo suficiente pa poder cenar esa noche. Recuerdo que fue en un bar que se llama (o llamaba) "Jamaica".

Es así como, tras quince meses de tesis doctoral, voy entendiendo mejor de qué manera están insertaslas marcas heredadas dela colonialidad, sus persistenciasy transformaciones, en mi familia y en mí, en el contacto con otros flamencos, en otros entornos, y con otras perspectivas. De la pluralidad de formas de sentir(se) y expresar flamenco(a) según las familias y las experiencias vitales personales, de las distintas formas de adscripción y autorepresentación como gitanos y flamencos, así como de aquellas posiciones que aluden a un colectivo y un flamenco homogéneo y unitario que no se encuentra más que 
en los prejuicios, estereotipos y representaciones coloniales sobre los otros (nosotros-as) subalternizados, sus/nuestros saberes y cosmovisiones.

Me doy más cuenta de por qué me dolía así y no de otra manera, y esto me ayuda no sólo a pensarme y pensar junto a otros(as) o a poner en relación con la memoria lo que he aprendido de las experiencias y las emociones, sino que está siendo un proceso de aprendizaje complejo, completo y total de memoria colectiva compartida. Y esto permite tomar con fuerza y desde los bordes, opciones y procesos demasiado complejos, mediados y medidos que dificultan pensar cantando: como es el caso de tener que articular estas cuestiones mediante la letra fija y el papel, con tan poco espacio para la improvisación, la creatividad, y el sonido compartido. Como dijo Tío Manué, "aquí cuándo se dice ole". La conversación sigue abierta. 


\section{REFERENCIAS BIBLIOGRÁFICAS}

Anzaldúa, Gloria (2012) Borderlands/La Frontera: The New Mestiza. San Francisco: Aunt Lute Books.

Barriendos, Joaquín (2007) "El arte global y las políticas de la movilidad. Desplazamientos (trans)culturales en el sistema internacional del arte contemporáneo". LiminaR. Estudios Sociales y Humanísticos, vol. 5, 1, pp. 159-182.

Castaño Madroñal, Ángeles (2015) “Colonialidad interna en Andalucía, del pasado al presente de su expolio”. Universidad de Coímbra. Material docente (sin publicar).

Cruces Roldán, Cristina (2002) Más allá de la música; Antropología y Flamenco (I). Sevilla: Signatura Ediciones.

Cruces Roldán, Cristina y Moreno Navarro, Isidoro (1996) El Flamenco: Identidades sociales, Ritual y Patrimonio Cultural. Sevilla: Centro Andaluz de Flamenco.

Estévez Trujillo, Mayra (2015) "Mis manos sonoras devoran la histérica garganta del mundo: sonoridades y colonialidad del poder". Calle 14, vol.10, 15, pp. 55-73.

García Lorca, Federico (1933) “Juego y Teoría del duende”. En Christopher Maurer (eds.) (1984) Conferencias/Federico García Lorca. Madrid: Alianza Editorial, pp. 87-109.

Hapanyengwi-Chemhuru, Oswell (2013) “Odera Oruka's four trends in African Philosophy and their implications for education in Africa". Thought and Practice: A Journal of the Philosophical Association of Kenya. New Series, vol.5, 2, pp. 39-55.

Espejo Arrebola, Juan Antonio (2011) "Las leyes y el flamenco". La Madrugá. Revista de Investigación sobre Flamenco, 4, pp. 21-36.

Gamella, Juan F. et al. (2011) “La agonía de una lengua. Lo que queda del caló en el habla de los gitanos. Parte I. Métodos, fuentes y resultados generales”. Gazeta de Antropología, 27(2), pp. 1-32.

García Olivares, Antonio (2003) "La filosofía de los cantes desgarrados: una epistemología popular". Revista Acciones e Investigaciones Sociales, 17, pp. 215-238.

Gimeno, Juan Carlosy Castaño Madroñal, Ángeles (2014) “Antropologíay descolonialidad. Desafíos etnográficos y descolonización de las metodologías". En VV.AA. Periferias, Fronteras y Diálogos. Una lectura antropológica de los retos de la sociedad actual. Tarragona: Universidad Rovira i Virgili. pp. 211-220.

Guerrero Arias, Patricio (2010) “Corazonar el sentido de las epistemologías dominantes desde las sabidurías insurgentes, para construir sentidos otros de la existencia”. Calle 14, vol.4, 5, pp. 81-95.

Haber, Alejandro.(2011) “Nometodología Payanesa: Notas demetodologíaindisciplinada”. Revista de Antropología, 23, pp. 9-49. 
Hernández León, Elodia y Castaño Madroñal, Ángeles (2014) "La geopolítica del conocimiento de la UNESCO y la semántica de interculturalidad en las políticas locales del patrimonio cultural". En Ángeles Castaño y Juan Carlos Gimeno (coord.): Antropología y Descolonialidad. Desafíos etnográficos y descolonización de las metodologías. Periferias, Fronteras y Diálogos. Tarragona: Actas del XIII Congreso de Antropología de la FAAEE, pp. 3580-3602.

Lizcano Fernández, Emmanuel (2006) "Las cuentecitas de los pobres. Crítica del saber culto y matemática paradójica del cante flamenco". En Emmanuel Lizcano Metáforas que nos piensan. Sobre ciencia, democracia y otras poderosas ficciones. Madrid: Ediciones Bajo Cero-Traficante de sueños, pp. 93-122.

Machado y Álvarez, Antonio [1871] (1998) Cantes flamencos recogidos y anotados por Antonio Machado y Álvarez (Demófilo). Barcelona: DVD ediciones.

Maldonado Torres, Nelson (2007) "Sobre la colonialidad del ser: contribuciones al desarrollo de un concepto". En Santiago Castro-Gómez y Ramón Grosfoguel (eds.). El giro decolonial. Reflexiones para una diversidad epistémica más allá del capitalismo global. Bogotá: Iesco-Pensar-Siglo del Hombre Editores, pp. 127-167.

Maldonado Torres, Nelson (2008) "La descolonización y el giro descolonial". Tabula Rasa. Revista de Humanidades, 9, pp. 61-72.

Mandly Robles, Antonio (2010) Los Caminos del Flamenco Etnografía, Cultura y Comunicación en Andalucía. Sevilla: Signatura ediciones.

Mandly Robles, Antonio y Llorente Martín, Fco. Manuel (2013) "Jugar con fuego. Flamenco, juegos de lenguaje y tecnologías de la comunicación". Gazeta de Antropología, 29(1).

Meneses, María Paula (2011) "Epistemologías del Sur: Diálogos que crean espacios para un encuentro de las historias". En VV.AA. IV Training Seminar del Foro de Jóvenes Investigadores en Dinámicas Interculturales (FJIDI). Barcelona: CIDOB ediciones, pp. 3141.

Mignolo, Walter (2010) Desobediencia epistémica: Retórica de la modernidad, lógicas de la colonialidad y gramática de la descolonialidad. Buenos Aires: Ediciones del Signo.

Mignolo, Walter (2010) “Aiesthesis decolonial”. Calle 14. Vol.4, 4, pp. 10-25.

Molina, Ricardo y Mairena, Antonio (1971). Mundo y formas del cante flamenco. Sevilla: Al-Ándalus.

Moreno Navarro, Isidoro (2002) La globalización y Andalucía: entre el mercado y la identidad. Sevilla: Mergablum. 
Ochoa, Ana María (2002) "El desplazamiento de los discursos de autenticidad: Una mirada desde la música”. Trans. Revista Transcultural de Música, 6. Disponible en: http:// www.redalyc.org/articulo.oa?id=82200608 [Consultado el 02 de diciembre de 2015]

Ong, Walter J. (2002) Oralidad y escritura. Tecnologías de la palabra. México: Fondo de Cultura Económica.

Ortega, Antonio (2015) "Flamencos y Cronopios". Programa de entrevistas a flamencos. 8tv Andalucía. Disponible en www.8tvandalucia.es/web/a-la-carta/ [Consultado el 22 de mayo de 2015]

Palermo, Zulma (2006) “Discursos heterogéneos, ¿más allá de la polifonía?”. Acta Poética, 27(1), pp. 213-243.

Palermo, Zulma (2009) (comp.) Arte y estética en la encrucijada descolonial. Buenos Aires: Ediciones del Signo.

Peña Fernández, Pedro (2013) Los gitanos flamencos. Córdoba: Almuzara.

Rappaport, Joanne (2008) "Beyond Participant Observation: Collaborative Ethnography as Theoretical Innovation". Collaborative Anthropologies, 1, pp. 1-31.

Reguillo Cruz, Rosanna (2008) "Subjetividad sitiada. Hacia una antropología de las pasiones contemporáneas". En Roberto Miranda y Lucía Mantilla (coord.) Espacio público y sociabilidad. Guadalajara: Universidad de Guadalajara. pp. 27-43.

Ríos Ruiz, Manuel (1972) Introducción al Cante Flamenco: Aproximaciones a la Historia $y$ a las Formas de un Arte Gitano-Andaluz. Madrid: Istmo

Saiko, Yuriko (2012) "La estética de lo cotidiano: creando mundo". Contrastes. Revista Internacional de Filosofía, 17, pp.255-274.

San Román, Teresa (1997) La diferencia inquietante: viejas y nuevas estrategias culturales de los gitanos. Madrid: Siglo XXI.

Sánchez Garrido, Pepa (2004) Cantes y cantaores de Triana. Sevilla: Los libros de la Bienal. Sousa Santos, Boaventura (2011) El milenio huérfano. Ensayos para una nueva cultura política. Madrid: Trotta/Ilsa.

Sousa Santos, Boaventura y Meneses, María Paula (eds.) (2014) Epistemologías del Sur (Perspectivas). Madrid: Akal.

Tlostonova, Madina (2011) "La aesthesis trans-moderna en la zona fronteriza euroasiática y el anti-sublime decolonial”. Calle 14. Revista de investigación en el campo del arte, v. 4, 6, pp.11-31.

Walsh, Catherine y García Salazar, Juan (2015) "Memoria colectiva, escritura y Estado. Prácticas pedagógicas de existencia afroecuatoriana”. Cuadernos de literatura, vol. 19, 38, pp. 79-98. 